\title{
Insights into Thymic Purine Metabolism and Adenosine Deaminase Deficiency Revealed by Transgenic Mice Overexpressing Ecto-5'-nucleotidase (CD73)
}

\author{
Regina Resta, ${ }^{\star \ddagger}$ Scott W. Hooker, ${ }^{\star}$ Aletha B. Laurent, ${ }^{\star}$ S.M. Jamshedur Rahman, ${ }^{\star}$ Melissa Franklin, ${ }^{\star \S}$ Thomas B. Knudsen, \\ Nancy L. Nadon," and Linda F. Thompson ${ }^{\star}$ \\ *Immunobiology and Cancer Program, Oklahoma Medical Research Foundation, Oklahoma City, Oklahoma 73104; ${ }^{\circ}$ Department of \\ Medicine and ${ }^{\S}$ Department of Microbiology and Immunology, University of Oklahoma Health Sciences Center, Oklahoma City, \\ Oklahoma 73104; "Department of Pathology, Anatomy, and Cell Biology, Jefferson Medical College, Philadelphia, Pennsylvania 19107, \\ and ${ }^{\mathbb{T}}$ Department of Biology, University of Tulsa, Tulsa, Oklahoma 74104
}

\begin{abstract}
The adenosine producing enzyme ecto- $5^{\prime}$-nucleotidase $\left(5^{\prime}-\mathrm{NT}\right)$ is not normally expressed during thymocyte development until the medullary stage. To determine whether earlier expression would lead to adenosine accumulation and/or be deleterious for thymocyte maturation, thymic purine metabolism, and $\mathrm{T}$ cell differentiation were studied in $l c k^{\mathrm{NT}}$ transgenic mice overexpressing $5^{\prime}-\mathrm{NT}$ in cortical thymocytes under the control of the lck proximal promoter. In spite of a 100 -fold elevation in thymic 5 '-NT activity, transgenic adenosine levels were unchanged and $\mathrm{T}$ cell immunity was normal. Inosine, the product of adenosine deamination, was elevated more than twofold, however, indicating that adenosine deaminase (ADA) can prevent the accumulation of adenosine, even with a dramatic increase in $5^{\prime}$-NT activity, and demonstrating the availability of $5^{\prime}-\mathrm{NT}$ substrates in the thymus for the first time. Thymic adenosine concentrations of mice treated with the ADA inhibitor 2' -deoxycoformycin (dCF) were elevated over 30-fold, suggesting that high ADA activity, rather than an absence of $5^{\prime}-\mathrm{NT}$, is mainly responsible for low thymic adenosine levels. The adenosine concentrations in dCF-treated mice are sufficient to cause adenosine receptor-mediated thymocyte apoptosis in vitro, suggesting that adenosine accumulation could play a role in ADA-deficient severe combined immunodeficiency. (J. Clin. Invest. 1997. 99:676-683.) Key words: P1 purinergic receptors $\cdot$ lymphocyte $\cdot 5$ '-nucleotidase $\cdot$ adenosine deaminase $\bullet$ severe combined immunodeficiency
\end{abstract}

\section{Introduction}

Purine metabolism changes during T cell development. In the human thymus, adenosine deaminase (ADA) ${ }^{1}$ activity is extraordinarily high in cortical thymocytes and is downregulated

A preliminary report of this work was presented at the Ninth International Congress of Immunology in San Francisco on July 25, 1995. Portions of this work were published in abstract form (Abstracts of the 9th International Congress of Immunology, p. 382).

Address correspondence to Dr. Linda F. Thompson, Oklahoma Medical Research Foundation, 825 N.E. 13th Street, Oklahoma City, OK 73104. Phone: 405-271-7235; FAX: 405-271-8568; E-mail: LindaThompson@omrf.uokhsc.edu

Received for publication 18 September 1996 and accepted in revised form 2 December 1996.

J. Clin. Invest.

(C) The American Society for Clinical Investigation, Inc. 0021-9738/97/02/0676/08 \$2.00

Volume 99, Number 4, February 1997, 676-683 at the medullary stage $(1,2)$. The importance of normal levels of ADA activity for T cell development is demonstrated dramatically by the appearance of severe combined immunodeficiency (SCID) in patients with certain mutations in the ADA gene which result in loss of enzyme activity (3). The lymphospecific toxicity that results is thought to be due largely to the accumulation of the ADA substrate deoxyadenosine and its subsequent conversion to dATP which inhibits ribonucleotide reductase, a key enzyme in DNA synthesis (4). Inhibition of methylation reactions by $S$-adenosyl homocysteine (SAH) formed by the condensation of adenosine plus homocysteine or accumulated because of the suicide inactivation of SAH hydrolase by ADA substrates may also contribute to SCID (5-7). It recently has been demonstrated that SAH can also function as a physiological modulator of APO-1(CD95)mediated cell death (8). The contribution of adenosine receptor signaling in ADA-deficient SCID is unknown. It is possible that adenosine itself engages receptors and contributes to $\mathrm{T}$ cell depletion in this disease given recent evidence that cAMP elevating agents such as adenosine receptor agonists cause apoptosis of thymocytes in vitro (9-11), and forskolin and the phosphodiesterase inhibitor 3-isobutyl-1-methyl-xanthine block thymocyte differentiation in fetal thymic organ culture (12).

Ecto-5'-nucleotidase ( $5^{\prime}$-NT, CD73) is another purine metabolic enzyme whose activity changes substantially during $\mathrm{T}$ cell development (1). Its pattern of expression is reciprocal to that of ADA, with $5^{\prime}$-NT activity virtually absent in cortical thymocytes and increasing in medullary thymocytes. The role of $5^{\prime}$-NT in thymocyte development is not well defined, and the reason for the regulated expression of this enzyme in the thymus is unknown. Since $5^{\prime}$-NT can produce extracellular adenosine and deoxyadenosine if the substrates AMP and dAMP are available, $5^{\prime}$-NT expression could be low in cortical thymocytes because its expression would be deleterious to immature thymocytes. Alternatively, $5^{\prime}$-NT expression may be turned on in the medulla because that is when the enzymatic activity is needed for normal thymocyte differentiation. To distinguish between these two possibilities and to gain insight into the function of $5^{\prime}$-NT in thymocyte development and purine metabolism, we created $l c k^{\mathrm{NT}}$ transgenic mice which overexpress $5^{\prime}$-NT in cortical thymocytes using the $l c k$ proximal promoter. This promoter is active only in thymocytes, and is turned off in mature peripheral T cells (13). Human (rather than murine) $5^{\prime}$-NT was chosen because of the ease of monitoring transgene expression with murine anti-human $5^{\prime}$-NT

1. Abbreviations used in this paper: ADA, adenosine deaminase; $\mathrm{dCF}$, 2'-deoxycoformycin; 5'-NT, ecto-5'-nucleotidase; SAH, S-adenosyl homocysteine; SCID, severe combined immunodeficiency. 
monoclonal antibodies. We hypothesized that increased expression of 5'-NT might lead to elevations in intrathymic adenosine levels to the point where adenosine receptor-mediated apoptosis would occur. However, in spite of a 100-fold elevation in $5^{\prime}$-NT activity over endogenous levels and the availability of $5^{\prime}$-NT substrates in the thymus, adenosine levels were unchanged and the $\mathrm{T}$ cell immunity of the $l c k^{\mathrm{NT}}$ transgenic mice was intact. An analysis of thymic purine metabolism revealed the central role of ADA in controlling adenosine levels in this tissue.

\section{Methods}

Production of lck $k^{N T}$ transgenic mice. The cDNA for the coding region of human 5'-NT [(14), gift of Dr. Yukio Ikehara, Fukuoka University, Fukuoka, Japan] was cloned into the SalI/BamHI sites of pSKII ${ }^{+}$ (Stratagene Inc., La Jolla, CA) using oligonucleotide linkers. This plasmid was digested with AvaI, which cuts immediately $3^{\prime}$ to the ATG translation initiation codon of the $5^{\prime}$-NT cDNA, and KpnI, which cuts in the polylinker proximal to the AvaI site. This vector was religated with an oligonucleotide encoding a KpnI site, a BamHI site, and the AvaI site preceded by the deleted ATG. The $5^{\prime}$-NT cDNA was removed by digestion with BamHI and ligated with the BamHI digested calf intestinal phosphatase-treated expression vector p1017 [(15) gift of Dr. Roger Perlmutter, University of Washington, Seattle, WA]. In the final construct, the human $5^{\prime}-\mathrm{NT}$ cDNA was located $3^{\prime}$ to a $3.2-\mathrm{kb}$ murine proximal lck promoter segment, and $5^{\prime}$ to a $2.1-\mathrm{kb}$ fragment of the human growth hormone gene that includes a single polyadenylation site (Fig. 1).

After being checked for proper orientation, the plasmid was digested with NotI and linear insert DNA was prepared. Transgenic animals were produced by pronuclear microinjection of $\mathrm{C} 57 \mathrm{Bl} / 6 \times \mathrm{C} 3 \mathrm{H}$ F1 zygotes (16). The presence of the transgene was detected by PCR on Proteinase K digested tail DNA with primers specific for the lck promoter in the forward direction and human $5^{\prime}$-NT in the reverse direction (Fig. 1). Amplification of a portion of the endogenous mouse thyroid stimulating hormone gene served as an internal control for the PCR.

Two transgenic lines were propagated under specific pathogenfree conditions by crossing independent male founder animals with $(\mathrm{C} 57 \mathrm{Bl} / 6 \times \mathrm{C} 3 \mathrm{H}) \mathrm{F} 1$ or $\mathrm{C} 57 \mathrm{Bl} / 6$ females. In all experiments, nontransgenic littermates served as age matched wild type controls. The cellularity of the thymus and spleen and cell surface phenotypes of thymocytes and peripheral lymphocytes were evaluated in both lines of mice and found to be similar. The remainder of the assays were done primarily with mice of line 1 .

Immunofluorescent staining. Single cell suspensions of thymus, spleen, and lymph nodes were prepared by passing the tissue through a fine mesh screen. Peripheral blood lymphocytes were isolated by density gradient centrifugation of diluted blood using Fico/Lite-LM (Atlanta Biologicals Inc., Norcross, GA). Cell surface antigens were detected by flow cytometry using a FACScan (Becton Dickinson, Mountain View, CA). Cells were stained with hybridoma superna- tants or purified mAbs as previously described in reference 17 using isotype-matched murine (Cappel Organon-Teknika, Malvern, PA) or rat (PharMingen, San Diego, CA) myeloma proteins as controls. The following antibodies were used: 1E9 ([18], anti-human CD73, IgG3), AD2 ([19], anti-human CD73, IgG1, gift of Dr. Max Cooper, University of Alabama, Birmingham, AL), biotin anti-murine CD3 (GibcoBRL, Gaithersburg, MD), FITC-anti-murine CD4, PE-anti-murine CD8, anti-I-Ek ${ }^{k}$, anti-V $\beta 5$, anti-V $\beta 8$, and anti-V $\beta 11$ (PharMingen). Biotin-anti-CD3 was detected with Cy-Chrome-streptavidin (PharMingen) and 1E9 and AD2 were detected with PE-goat anti-mouse IgG3 (Southern Biotechnology Associates, Birmingham, AL) and PE-goat anti-mouse IgG1 (Caltag Labs., San Francisco, CA), respectively. Data were collected on 10,000 cells for single color stains and on 20,000 cells for three color stains.

Ecto-5'-nucleotidase enzyme assay. 5'-NT enzyme activity was determined by measuring the conversion of $\left[{ }^{14} \mathrm{C}\right]$ inosine $5^{\prime}$-monophosphate to $\left[{ }^{14} \mathrm{C}\right]$ inosine by whole cells as described in reference 20 . The results are expressed as nmol product formed/h per $10^{6}$ viable cells, and are the means of at least triplicate determinations from which nonspecific phosphatase activity has been subtracted.

Negative selection. The percentage of T cells bearing V 35 and V $\beta 11$ was determined in 100,000 cells by two color staining of lymph node cells from control and $l c k^{\mathrm{NT}}$ transgenic mice for $\mathrm{V} \beta$ and $\mathrm{CD} 3$. Female $l c k^{\mathrm{NT}}$ transgenic mice were bred to homozygous male $\mathrm{H}-\mathrm{Y}$ TCR transgenic mice ([21], gift of Dr. Janko Nikolic-Zugic, Memorial Sloan Kettering Cancer Center, New York). At 12-14 d of age, male mice were killed and their thymuses were examined for cellularity and the expression of the $l c k^{\mathrm{NT}}$ and H-Y TCR transgenes.

Thymic recovery after sublethal irradiation. Six 3-wk-old transgenic mice and six control littermates were subjected to sublethal irradiation (750 rad). Thymus cellularity and thymocyte subsets were determined at $1,4,9$, and $14 \mathrm{~d}$.

$T$ cell activation assay. Single cell suspensions of thymocytes and splenocytes from transgenic mice and control littermates were cultured in flat-bottomed microtiter plates at $10^{6}$ cells $/ \mathrm{ml}$ in RPMI $1640+$ $10 \%$ FBS, $2 \mathrm{mM}$ glutamine, penicillin $(100 \mathrm{U} / \mathrm{ml})$, streptomycin $(100 \mu \mathrm{g} / \mathrm{ml})$, amphotericin B $(0.25 \mu \mathrm{g} / \mathrm{ml})$, and $5 \times 10^{-5} \mathrm{M} 2-\mathrm{ME}$. The hamster anti-murine CD3 mAb 145-2C11 ([22], gift of Dr. Jeffrey Bluestone, University of Chicago, Chicago, IL) was added either in solution or immobilized at the indicated concentrations. For immobilization, the mAb 145-2C11 was added to microtiter wells in PBS for $2 \mathrm{~h}$ at room temperature. The wells were then washed twice with PBS to remove unbound $\mathrm{mAb}$ and blocked with complete medium for $1 \mathrm{~h}$ at room temperature. PMA (Sigma Chemical Co., St. Louis, MO) was dissolved in DMSO at $1 \mathrm{mg} / \mathrm{ml}$ and aliquots were frozen and stored at $-20^{\circ} \mathrm{C}$ until used at $10-\mathrm{ng} / \mathrm{ml}$. After $44-68 \mathrm{~h}$ of culture, the cells were pulsed with $1 \mu \mathrm{Ci}\left[{ }^{3} \mathrm{H}\right]$ thymidine/well for $4 \mathrm{~h}$. The cells were collected onto glass fiber filters with a multiple automated sample harvester and the amount of radioactivity incorported into DNA was determined by liquid scintillation counting. All culture conditions were performed in triplicate.

ELISA for serum immunoglobulins. Serum levels of IgG1, IgG2a, IgG2b, IgG3, IgM, and IgA were determined by ELISA (Southern Biotechnology Associates).

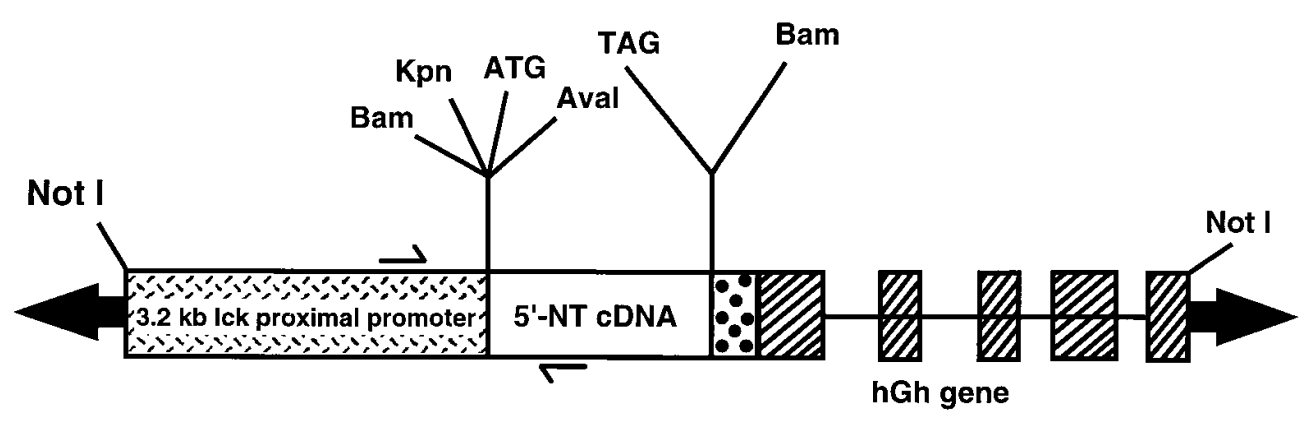

Figure 1. Vector used to make transgenic mice. Translation initiation and termination codons are shown. Murine $l c k$ promoter is in hatched bars, followed by the human 5'-NT cDNA and the untranslated human growth hormone gene with introns. The primers used for PCR to identify transgenic animals and the Not I sites used to linearize the vector are also indicated. 
Immunization for anti-OVA. Transgenic mice and control littermates were immunized with $25 \mu \mathrm{g}$ ovalbumin in CFA i.p. One month later, they were boosted with $25 \mu \mathrm{g}$ ovalbumin in incomplete Freund's adjuvant (IFA) i.p. They were bled $10 \mathrm{~d}$ later and serum antibodies against ovalbumin were measured by ELISA. Briefly, polyvinyl microtiter plates were coated with ovalbumin at $10 \mu \mathrm{g} / \mathrm{ml}$. Serial dilutions of mouse sera were added to the wells and the anti-ovalbumin antibodies were detected with alkaline phosphatase conjugated goat anti-mouse Ig (Caltag Labs.).

Bacterial challenges. Recently weaned transgenic mice and control littermates were challenged with single i.p. injections of the following pathogens: Listeria monocytogenes (local hospital strain, $4.5 \times$ $10^{7}$ organisms/g), Escherichia coli (American Type Culture Collection, Rockville, MD ATCC 25922, 1.6-2.4 × 106 bacteria/g), Haemophilus influenzae (ATCC 35056, $8.5 \times 10^{7}$ bacteria/g), and Streptococcus pneumoniae (ATCC 6303, $10^{9}$ bacteria/mouse).

HPLC to measure thymic adenosine/inosine. Mice (4-8 wk of age) were killed by cervical dislocation and one half of the thymus was homogenized in $0.85 \mathrm{ml}$ of ice cold $0.4 \mathrm{~N} \mathrm{HClO}_{4}$ as described in reference 23. The samples were placed on ice for $15 \mathrm{~min}$ and then centrifuged for $2 \mathrm{~min}$ at full speed in a microfuge at $4^{\circ} \mathrm{C}$. The supernatants were transferred to a clean tube and $0.1 \mathrm{ml}$ was removed for protein determination. The remaining volume $(0.685 \mathrm{ml})$ was neutralized with $0.345 \mathrm{ml}$ of $0.6 \mathrm{M} \mathrm{KHCO}_{3} / 0.72 \mathrm{M} \mathrm{KOH}$. The samples were clarified by centrifugation for $1-2 \mathrm{~min}$ at full speed in a microfuge at $4^{\circ} \mathrm{C}$ and then analyzed by HPLC using a $0.50-\mathrm{ml}$ injection volume. The amounts of adenosine and inosine in each sample were calculated from the areas under the respective peaks using authentic standards and an internal peak to correct for variations in extraction efficiency and sample loading as previously described (24). The remaining half of the thymus was used to confirm the transgene status of the mice.

Thymocyte culture and evaluation of apoptosis. Thymocyte suspensions $\left(2.5 \times 10^{6}\right.$ cells $)$ from transgenic mice and control littermates were cultured overnight in 24-well flat-bottomed multi-well plates in $1 \mathrm{ml}$ of complete medium at $37^{\circ} \mathrm{C}$ in an atmosphere of $5 \%$ $\mathrm{CO}_{2}$ in air in the presence of various concentrations of adenosine receptor agonists. The percentage of apoptotic cells was determined by cell cycle analysis with propidium iodide staining (25). Briefly, $2.5 \times 10^{6}$ cells were resuspended in $0.29 \mathrm{ml}$ PBS $+50 \%$ FBS and ice cold $95 \%$ ethanol was added to give a final concentration of $50 \%$. The cells were kept at $4^{\circ} \mathrm{C}$ for at least $15 \mathrm{~min}$ or as long as overnight. The cells were then harvested, resuspended in $1 \mathrm{ml}$ PBS containing propidium iodide at $50 \mu \mathrm{g} / \mathrm{ml}$ and DNase-free RNase A at $5 \mathrm{U} / \mathrm{ml}$, and incubated at $37^{\circ} \mathrm{C}$ for $45 \mathrm{~min}$. After incubation, the cells were immediately analyzed with a FACScan. Cells containing less than the $\mathrm{G}_{0} / \mathrm{G}_{1}$ content of DNA were considered to be apoptotic. Water soluble dexamethasone (Sigma Chemical Co.) was used as a positive control and routinely induced apoptosis in $>65 \%$ of the thymocytes.

\section{Results}

Expression of the transgene in lymphoid tissue. Human 5'-NT expression in $l c k^{\mathrm{NT}}$ mice was evaluated by both immunofluorescence and enzyme assay. By immunofluorescence, human $5^{\prime}$-NT was detected on the majority of T cells in the thymus, peripheral blood (Fig. 2), spleen, and lymph node, and expression persisted in these sites in older ( $>1 \mathrm{yr}$ ) mice (Fig. 3 ). The transgene was anchored to the cell surface via glycosyl phosphatidylinositol (as is the endogenous gene) as shown by its sensitivity to removal by Bacillus thuringiensis phosphatidylinositol-specific phospholipase C (data not shown) (gift of Dr. Martin Low, Columbia University, New York). Human 5'-NT expression was retricted to $\mathrm{T}$ lineage cells as demonstrated by two-color immunofluorescence with CD3 and 5'-NT mAbs (Fig. 2). Even in mice over $1 \mathrm{yr}$ of age, human $5^{\prime}$-NT expression was maintained at high levels in the thymus and periph-

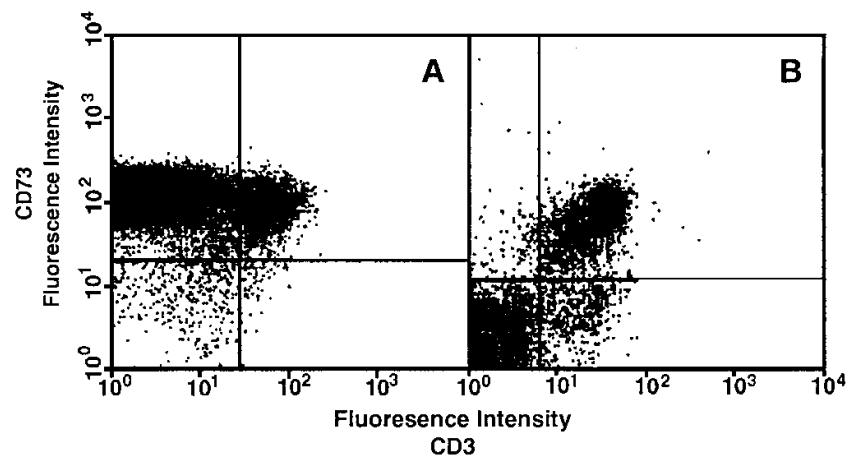

Figure 2. Human $5^{\prime}$-NT expression on thymocytes and peripheral blood mononuclear cells of transgenic mice. Thymocytes $(A)$ and peripheral blood mononuclear cells $(B)$ of a $24-\mathrm{d}$ old $l c k^{\mathrm{NT}}$ mouse were isolated and stained with anti-human CD73 and anti-murine CD3 mAbs as described. 20,000 cells were analyzed and the positions of the quadrants set using isotype matched control antibodies. Similar results were obtained with eight transgenic mice.

eral lymphoid organs (Fig. 3). Since monoclonal antibodies specific for murine $5^{\prime}$-NT are not available, the increase in $5^{\prime}$-NT expression in transgenic mice versus control littermates was evaluated by $5^{\prime}$-NT enzyme assays (Table I). These demonstrated a 100-fold increase in 5'-NT enzyme activity in the thymus and a threefold increase in spleen. The lower fold increase in the spleen was caused by three factors: first, endogenous $5^{\prime}-\mathrm{NT}$ activity is fourfold higher in spleen than in thymus;

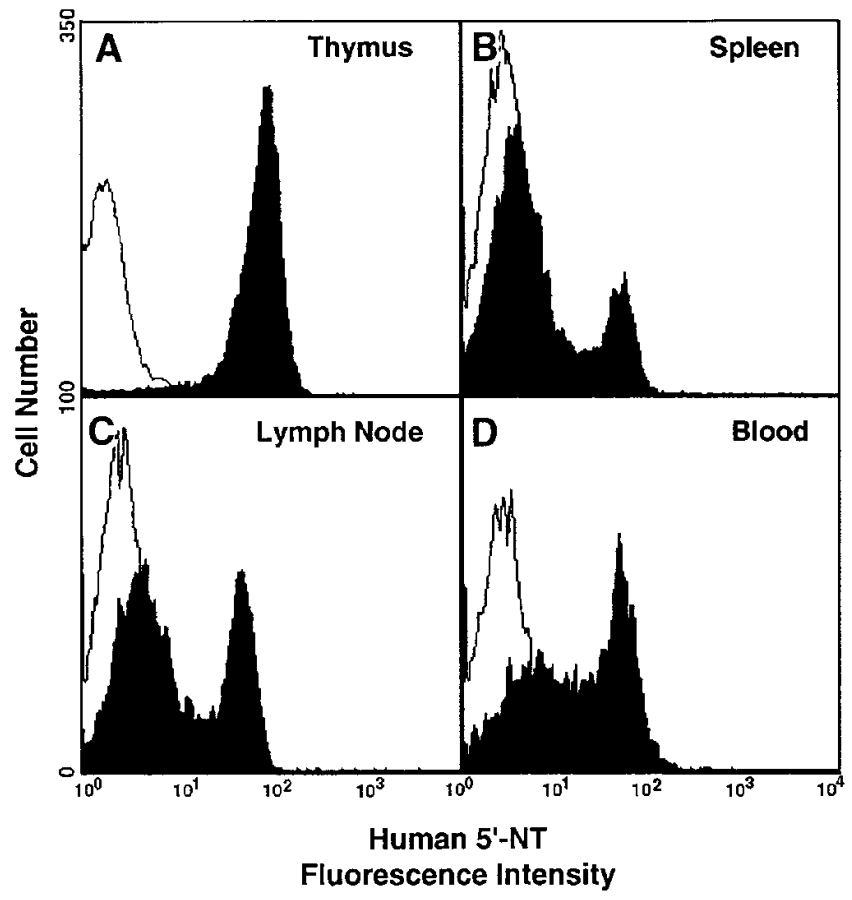

Figure 3. Human 5'-NT expression in lymphoid tissue of old transgenic mice. Single cell suspensions of thymocytes $(A)$, splenocytes $(B)$, lymph node cells $(C)$, or peripheral blood mononuclear cells $(D)$ of a 13.5 month old $l c k^{\mathrm{NT}}$ transgenic mouse were stained with the human 5'-NT-specific mAb AD2 (solid histogram) or an isotype matched control antibody (open histogram) followed by PE-antiIgG1. Similar results were obtained with 17 transgenic mice ranging in age from $12 \mathrm{~d}-6$ mo. 
Table I. 5'-NT Enzyme Activity in Thymocytes and Spleen Cells from Control and Transgenic Mice

\begin{tabular}{llc}
\hline & \multicolumn{2}{c}{$5^{\prime}$-NT Activity $\left(\mathrm{nmol} / \mathrm{h} / 10^{6}\right.$ cells)* } \\
\cline { 2 - 3 } & Control & $l c k^{\mathrm{NT}}$ \\
\hline Spleen & 2.6 & 8.3 \\
Thymus & 0.65 & 65 \\
& & \\
\hline
\end{tabular}

* $5^{\prime}$-NT enzyme activity was measured on cell suspensions as described in Methods. The results are the means of triplicate determinations from which nonspecific phosphatase activity is subtracted. Replicate measurements varied by less than $10 \%$. Similar results were obtained with a second pair of control and transgenic mice.

second, only $\sim 20 \%$ of splenocytes are T cells; and third, transgene expression was slightly lower in spleen than in thymus as evaluated by indirect immunofluorescence (Fig. 3). Human $5^{\prime}$-NT mRNA was expressed only in thymus as determined by Northern blot analysis of thymus, spleen, liver, heart, kidney, lung, brain, stomach, small intestine, and colon RNA, using a probe specific for human growth hormone sequences contained in the vector used to generate the transgenic mice (not shown). Continued expression of $5^{\prime}$-NT in peripheral T cells, even in older mice, differs from what one usually sees with transgenes under the control of the proximal lck promoter as this promoter is not active once $\mathrm{T}$ cells leave the thymus (13). Our findings could be due to either an extraordinarily long half-life for the $5^{\prime}$-NT protein, or to aberrant activity of the lck proximal promoter in our transgene construct. However, it is likely that $5^{\prime}$-NT protein has a long half-life, given the absence of human $5^{\prime}$-NT transcripts by Northern blot in spleen and the known extensive recycling of $5^{\prime}$-NT from the cell surface to intracellular pools and back (26).

Cellularity of lymphoid tissue. Transgenic and control mice were evaluated for thymus and spleen cellularity at various ages beginning at $12 \mathrm{~d}$. Although there was considerable variability from animal to animal, the average size of the thymus and spleen was the same in the transgenic mice as in their control littermates (Table II).

Analysis of $T$ cell phenotypes. To look for abnormalities in $\mathrm{T}$ cell development, $\mathrm{T}$ lineage cells from thymus, spleen, peripheral blood, and lymph node were examined for cell surface expression of CD3, CD4, and CD8 using multi-color flow cytometry beginning at day 12 of life. No abnormalities in the percentages of major thymocyte subsets; i.e., $\mathrm{CD} 4^{-} \mathrm{CD} 8^{-}$, $\mathrm{CD}^{+} \mathrm{CD}^{+}, \mathrm{CD}^{+}{ }^{+} \mathrm{CD} 8^{-}$, or $\mathrm{CD} 4^{-} \mathrm{CD} 8^{+}$cells were seen at any age (data not shown). The percentages of thymus, spleen, lymph node, and peripheral blood lymphocytes expressing

Table II. Lymphoid Organ Cellularity of Control and Transgenic Mice

\begin{tabular}{lcc}
\hline & Control mice & $l c k^{\mathrm{NT}}$ mice \\
\cline { 2 - 3 } & \multicolumn{2}{c}{ Millions of cells* } \\
\hline Thymus & $227 \pm 42(n=9)$ & $237 \pm 110(n=8)$ \\
Spleen & $89 \pm 32(n=4)$ & $103 \pm 62(n=6)$
\end{tabular}

*Thymus and spleen cellularity were evaluated in 24-41-d old mice of the indicated genotypes.
Table III. Negative Selection of T Cells Bearing V $\beta 5$ and V $\beta 11$ in Control and lck $^{N T}$ Mice

\begin{tabular}{lcc}
\hline & \multicolumn{2}{c}{$\%$ of $\mathrm{CD}^{+}$lymph node cells* } \\
\cline { 2 - 3 } Mice & $\mathrm{V} \beta 5^{+}$ & $\mathrm{V} \beta 11^{+}$ \\
\hline $\mathrm{I}^{\mathrm{k}} \mathrm{E}^{\mathrm{k}-}, l c k^{\mathrm{NT}-}(n=5)$ & $7.6 \pm 0.6$ & $6.2 \pm 1.1$ \\
$\mathrm{I}^{\mathrm{k}-}, \mathrm{E}^{\mathrm{NT}+}(n=4)$ & $7.5 \pm 0.5$ & $6.4 \pm 0.8$ \\
$\mathrm{I}^{\mathrm{k}+}, \mathrm{E}^{\mathrm{N}+} k^{\mathrm{NT}-}(n=4)$ & $0.28 \pm 0.04$ & $1.8 \pm 0.3$ \\
$\mathrm{I}^{\mathrm{k}} \mathrm{E}^{\mathrm{k}+}, l c k^{\mathrm{NT}+}(n=5)$ & $0.49 \pm 0.2$ & $1.7 \pm 0.8$
\end{tabular}

*The percentages (mean $\pm \mathrm{SD}$ ) of $\mathrm{CD}^{+}$lymph node $\mathrm{T}$ cells bearing $\mathrm{T}$ cell receptor V $\beta 5$ or V $\beta 11$ were determined in 6-12-wk old mice of the indicated $I-E^{k}$ and transgene status using two-color flow cytometry. 50,000 cells were analyzed for the $\mathrm{I}-\mathrm{E}^{\mathrm{k}-}$ mice and 100,000 cells for the $\mathrm{I}-\mathrm{E}^{\mathrm{k}+}$ mice.

CD3, as well as the density of CD3, were also normal in transgenic mice as compared to their control littermates. Likewise, the percentages of $\mathrm{CD}^{+}$and $\mathrm{CD}^{+} \mathrm{T}$ cells were normal in spleen, peripheral blood, and lymph node (data not shown).

Evaluation of negative selection. Since the numbers of single positive thymocytes were normal in the transgenic mice, we concluded that postive selection was intact. Two strategies were undertaken to evaluate negative selection. First, the dele-

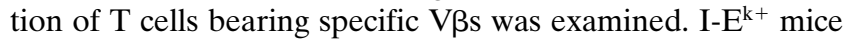
delete $\mathrm{T}$ cells bearing $\mathrm{T}$ cell receptors containing $\mathrm{V} \beta 5$ or $\mathrm{V} \beta 11$ (27). This process occurred normally in $l c k^{\mathrm{NT}}$ transgenic mice which were also I-E $\mathrm{E}^{\mathrm{k}+}$ (Table III). Next, we evaluated the ability of $l c k^{\mathrm{NT}}$ transgenic mice to delete $\mathrm{T}$ cells bearing a TCR recognizing nominal antigen. This was done by crossing female $l c k^{\mathrm{NT}}$ mice with male homozygous $\mathrm{H}-\mathrm{Y}$ TCR transgenic mice. Male offspring that were positive for the $l c k^{\mathrm{NT}}$ transgene had marked reductions in thymus cellularity similar to that seen in $l c k^{\mathrm{NT}-} \mathrm{H}-\mathrm{Y}$ TCR transgenic mice (Table IV), consistent with the deletion of $\mathrm{CD}^{+} \mathrm{CD}^{+}$thymocytes recognizing the $\mathrm{H}-\mathrm{Y}$ antigen. Thus, we conclude that negative selection is also normal in $l c k^{\mathrm{NT}}$ transgenic mice.

Recovery of $T$ cells after sublethal irradiation. Although the steady state numbers of thymocytes were normal in $l c k^{\mathrm{NT}}$ transgenic mice, we wondered whether the rate of generation of new thymocytes was normal. Therefore, transgenic mice and control littermates were subjected to sublethal irradiation and the kinetics of thymic repopulation were compared. For both transgenic and control mice, the number of cells in the thymus reached a low on day 4 , and the kinetics of repopulation of all thymocyte subsets were indistinguishable in the two groups of mice (data not shown).

Table IV. Thymus Cellularity in lck ${ }^{N T} \times H-Y T C R$ Transgenic Mice

\begin{tabular}{|c|c|}
\hline Mice & Thymus cellularity* \\
\hline $\mathrm{O}^{\top} \mathrm{H}-\mathrm{Y} \mathrm{TCR}^{+}, l c k^{\mathrm{NT}-} n=16$ & $28 \pm 5 \times 10^{6}$ cells \\
\hline$\sigma^{7} \mathrm{H}-\mathrm{Y} \mathrm{TCR}{ }^{+}, l c k^{\mathrm{NT}+} n=13$ & $29 \pm 8 \times 10^{6}$ cells \\
\hline ㅇ H-Y TCR ${ }^{+}, l c k^{\mathrm{NT}-} n=18$ & $71 \pm 19 \times 10^{6}$ cell \\
\hline
\end{tabular}

*Thymus cellularity (mean \pm SD) was evaluated in 12-14-d old mice of the indicated phenotypes. 
Measurement of $T$ cell proliferation in response to anti-CD3 stimulation. Thymocytes and spleen cells from transgenic mice and control littermates were compared for their ability to proliferate in response to anti-CD3 stimulation. Anti-CD3 was used in both soluble and immobilized form, and at a large range of concentrations $(10 \mathrm{ng} / \mathrm{ml}-1 \mu \mathrm{g} / \mathrm{ml}$ for soluble antiCD3 and $10 \mathrm{ng} / \mathrm{ml}-10 \mu \mathrm{g} / \mathrm{ml}$ for immobilized $\mathrm{mAb}$ ), and in the presence and absence of PMA at $10 \mathrm{ng} / \mathrm{ml}$. Under all conditions, thymocytes and spleen cells from transgenic mice made responses which were comparable to those of their control littermates (data not shown).

Evaluation of serum immunoglobulin levels. Humoral immunity was evaluated by measuring both total immunoglobulins as well as the ability to make a specific antibody response to the T cell-dependent antigen ovalbumin. Total IgG1, IgG2a, IgG2b, IgG3, IgA, and IgM serum levels were comparable between 10 transgenic mice and 10 age-matched control littermates (data not shown). Antiovalbumin titers were also similar in a group of six transgenic mice and six control littermates (data not shown).

Reproduction, life span, and susceptibility to infection. The transgenic mice appeared healthy and reproduced at a normal rate. Out of 362 mice analyzed from line 1, 44\% were transgene positive, and out of 90 analyzed from line 2, 54\% were transgene positive. The life expectancy of the transgenic mice is normal, with the oldest mice now at 24 mo of age. Thus, the $l c k^{\mathrm{NT}}$ transgene is not deleterious for either reproduction or survival. The transgenic mice showed no increase in susceptibility to infection with $L$. monocytogenes, $E$. coli, $H$. influen$z a e$, and $S$. pneumoniae and responded normally to challenge with LPS.

Thymocyte apoptosis induced by general and $A_{2 a}$ adenosine receptor agonists. Murine thymocytes express $\mathrm{A}_{2 \mathrm{a}}, \mathrm{A}_{2 \mathrm{~b}}$, and $\mathrm{A}_{3}$ adenosine receptors (28-30). The $\mathrm{A}_{2 \mathrm{a}}$ and $\mathrm{A}_{2 \mathrm{~b}}$ receptors are positively coupled to adenylate cyclase, while $\mathrm{A}_{3}$ receptor signaling is mediated through phospholipase $\mathrm{C}$ activation or decreases in cAMP (31). Since cAMP can induce thymocyte apoptosis (10-12), increases in thymic adenosine levels sufficient to engage $A_{2 a}$ or $A_{2 b}$ receptors might be expected to lead to increased rates of apoptosis and decreased organ cellularity. Bursch and colleagues predict that even an apoptosis rate as low as $0.5 \% / \mathrm{h}$ can lead to a $25 \%$ change in organ cellularity over a period of several days (32). However, the percentages of apoptotic cells were similar in frozen thymic sections from control and transgenic mice as detected by the terminal deoxynucleotidyl transferase-mediated dUTP-biotin nick end-labeling (TUNEL) assay (data not shown). The failure to find increased percentages of apoptotic cells in thymic sections and normal thymus cellularity suggest that adenosine levels do not accumulate in these mice to the point where apoptosis is induced.

Thymocyte suspensions from normal and transgenic mice also showed similar increases in the percentages of apoptotic cells when treated with the general adenosine receptor agonist, [5'-(N-ethyl)-carboxamidoadenosine], (NECA), or the $\mathrm{A}_{2 \mathrm{a}}$ receptor specific agonist, [2-[p-(carboxyethyl)phenylethylamino]5' ethyl-carboximadoadenosine] (CGS21680) (Table V). No increase in apoptosis was seen with the $\mathrm{A}_{1}$ receptor agonist N6-cyclopentyladenosine (CPA). The specificity of the adenosine receptor agonists was confirmed by the ability of the adenosine receptor antagonist 8-phenyltheophylline (8-PT) to inhibit the responses (data not shown). These results confirm the
Table V. Apoptosis in Thymocytes of Control and lck ${ }^{\mathrm{NT}}$ Transgenic Mice

\begin{tabular}{|c|c|c|c|c|c|}
\hline & \multicolumn{5}{|c|}{ Treatment* } \\
\hline & None & $\begin{array}{l}100 \mathrm{nM} \\
\mathrm{NECA}\end{array}$ & $\begin{array}{c}100 \mathrm{nM} \\
\mathrm{CGS} 21680\end{array}$ & $\begin{array}{c}10 \mathrm{nM} \\
\mathrm{CPA}\end{array}$ & $\begin{array}{c}10 \mathrm{nM} \\
\text { Dex }\end{array}$ \\
\hline & \multicolumn{5}{|c|}{$\%$ apoptotic cells $(\text { mean } \pm S D)^{\ddagger}$} \\
\hline Control & $22 \pm 2$ & $35 \pm 4$ & $34 \pm 3$ & $25 \pm 2$ & $76 \pm 2$ \\
\hline$l c k^{\mathrm{NT}}$ & $26 \pm 1$ & $33 \pm 3$ & $35 \pm 2$ & $28 \pm 2$ & $69 \pm 6$ \\
\hline
\end{tabular}

*Control $(n=3)$ or transgenic $(n=4)$ thymocyte suspensions were incubated for $10 \mathrm{~h}$ at $37^{\circ} \mathrm{C}$ in complete medium containing the indicated reagents. ${ }^{\ddagger}$ The percentages (mean $\pm \mathrm{SD}$ ) of apoptotic cells were determined by staining with propidium iodide and calculating the percentages of cells in the sub- $\mathrm{G}_{0} / \mathrm{G}_{1}$ peak during cell cycle analysis.

observations of Kizaki et al. (10) and McConkey et al. (11) and reveal that $A_{2 a}$ receptors specifically are capable of mediating apoptosis in thymocytes. It is possible that $\mathrm{A}_{2 \mathrm{~b}}$ receptors also contribute, as specific agonists are not yet available for this receptor subtype. The spontaneous apoptosis seen in both groups of animals was not inhibited by 8-PT, however, suggesting that it is not mediated by adenosine receptor engagement.

Measurement of thymic nucleoside levels in the transgenic mice. Adenosine measurements in thymic extracts revealed that adenosine concentrations were only moderately elevated in the trangenic mice as compared to age-matched control littermates, $2.0 \pm 0.8 \mu \mathrm{M}$ versus $1.4 \pm 1.3 \mu \mathrm{M}$, and this difference was not statistically significant $(P=0.159)$ as assessed by a Mann-Whitney rank sum test (Table V). Thymic inosine concentrations, however, were approximately twofold elevated in the transgenic mice $(60 \pm 28$ versus $28 \pm 10 \mu \mathrm{M})$, and this difference was highly significant as assessed by both a Student's $t$ test $(P=0.02)$ and a Mann-Whitney rank sum test $(P=$ 0.006). Since inosine is the product of adenosine catabolism, these results demonstrate for the first time that $5^{\prime}$-NT substrates are available in the thymus, but adenosine fails to accumulate because it is metabolized to inosine either directly via ADA or indirectly via adenosine kinase, AMP deaminase, and cytoplasmic $5^{\prime}$-NT, another purine salvage pathway enzyme distinct from ecto-5'-NT (Fig. 4).

A second approach to estimating the amount of adenosine produced by the transgene was undertaken by comparing aden-

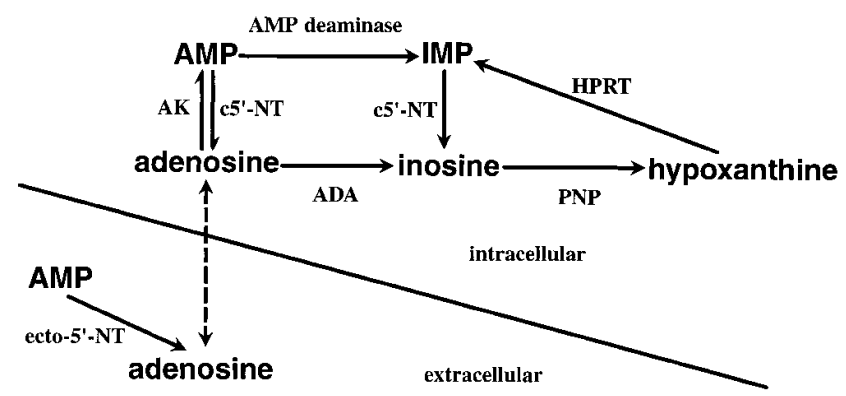

Figure 4. The purine salvage pathway. AK, adenosine kinase; ADA, adenosine deaminase; PNP, purine nucleoside phosphorylase; HPRT, hypoxanthine phosphoribosyltransferase; $\mathrm{c5}^{\prime}$-NT, cytoplasmic 5'-nucleotidase; ecto-5'-NT, ecto-5' -nucleotidase, CD73. 
Table VI. Thymic Nucleoside Concentrations in Control and lck ${ }^{N T}$ Transgenic Mice

\begin{tabular}{lcc}
\hline & Adenosine $^{\text {*‡ }}$ & Inosine $^{\S}$ \\
\hline Control mice $(n=7)$ & $1.4 \pm 1.3 \mu \mathrm{M}$ & $28 \pm 10 \mu \mathrm{M}$ \\
$l c k^{\mathrm{NT}}$ mice $(n=7)$ & $2.0 \pm 0.8 \mu \mathrm{M}$ & $60 \pm 28 \mu \mathrm{M}$
\end{tabular}

*Adenosine and inosine levels were measured in thymic extracts of $l c k^{\mathrm{NT}}$ transgenic mice and control littermates by HPLC as described in Methods. These levels were converted to concentrations by estimating the average thymus size of a young (4-8 wk old) mouse to be $0.05 \mathrm{ml}$ and assuming that the nucleosides are equally distributed between the intra- and extracellular space since they are free to diffuse across the cell membrane. ${ }^{\ddagger} P=0.159$ by a Mann-Whitney rank sum test. ${ }^{\S} P=0.02$ by a Student's $t$ test and $P=0.006$ by a Mann-Whitney rank sum test.

osine levels in control and transgenic mice treated for $3 \mathrm{~h}$ with $5 \mathrm{mg} / \mathrm{kg}$ of the ADA inhibitor 2'-deoxycoformycin (dCF). The average adenosine content in the thymuses of two dCF-treated control mice was $54 \mu \mathrm{M}$ as compared to $96 \mu \mathrm{M}$ for two agematched transgenic mice. Thymic deoxyadenosine was elevated to similar concentrations. The difference in adenosine levels between dCF-treated transgenic and control mice agrees well with the elevation in inosine levels in untreated transgenic mice. This lends support to the conclusion that the elevated inosine in the thymuses of the transgenic mice derives from the breakdown of extracellular AMP to adenosine catalyzed by the transgene, followed by the breakdown of adenosine to inosine, catalyzed in large part by ADA.

\section{Discussion}

Transgenic mice overexpressing $5^{\prime}$-NT in cortical thymocytes were created to study the role of this adenosine producing enzyme in T cell development and function and in the control of thymic adenosine levels. Since our experiments, as well as those of others $(10,11)$, demonstrated that adenosine receptor agonists induce apoptosis of thymocytes in vitro, we postulated that overexpression of $5^{\prime}-\mathrm{NT}$ in the thymus might lead to increased adenosine levels, adenosine receptor-mediated apoptosis, and aberrations in thymus development. Thus, the proximal $l c k$ promoter was used to target $5^{\prime}$-NT to cortical thymocytes, which are normally $5^{\prime}-\mathrm{NT}^{-}$. The expression of the $5^{\prime}$-NT transgene, however, had no effect on spontaneous thymocyte apoptosis in vitro as assessed by overnight culture, or in vivo as assessed by TUNEL assay. Furthermore, no defect in thymocyte differentiation or function was found in extensive evaluation of these mice. The transgenic mice had normal cellularity of the spleen, thymus, peripheral blood, and lymph nodes with normal lymphocyte subsets. Positive selection and negative selection to superantigen and nominal antigen were unaltered. The mice exhibited a normal antibody response to the T-dependent antigen ovalbumin, and a normal proliferative response to anti-CD3. Their susceptibilty to both LPS and a number of bacterial pathogens was unaffected, as was thymic recovery after sublethal radiation.

Our inability to find any defects in T cell development or cellular immunity in the $l c k^{\mathrm{NT}}$ transgenic mice led us to consider that thymic adenosine levels might not be significantly altered in spite of the fact that the activity of $5^{\prime}$-NT was elevated 100 -fold. Direct measurements of thymic adenosine concentra- tions confirmed this to be true with the transgenic mice showing only moderately elevated thymic adenosine $(2.0 \mu \mathrm{M})$ as compared to their control littermates $(1.4 \mu \mathrm{M})$. The unaltered adenosine concentrations were not caused by a lack of $5^{\prime}$-NT substrates in the thymus, however, as the concentrations of inosine (the next metabolite in the purine salvage pathway) were elevated about twofold from $28-60 \mu \mathrm{M}$. To our knowledge, this is the first demonstration that extracellular substrate for $5^{\prime}-\mathrm{NT}$ is available in the thymus in vivo. It had been hypothesized that extracellular substrate for $5^{\prime}$-NT would exist in sites of massive cell death or apoptosis such as the thymus (33), and our findings substantiate this prediction. Thus, there is sufficient extracellular AMP such that if all the "extra" inosine derived via the action of the transgene were trapped as adenosine, we would expect more than a 20 -fold increase in thymic adenosine concentrations from 1.4-33 $\mu \mathrm{M}$ [i.e., $32 \mu \mathrm{M}(60-28)+$ $1.4 \mu \mathrm{M}]$. This tremendous potential of $5^{\prime}-\mathrm{NT}$ to contribute to adenosine production in the thymus has not been previously appreciated. However, even in the face of a 100-fold elevation in adenosine producing activity in the thymus provided by the $5^{\prime}$-NT transgene, the ADA substrate adenosine does not accumulate, suggesting that it is the high levels of ADA rather than low levels of 5'-NT that are responsible for maintaining low thymic adenosine levels. Thus, the purine metabolic machinery of the thymus seems to have evolved to maintain low adenosine levels in the face of a large supply of extracellular nucleotides. The importance of this pathway is illustrated by the severe $T$ cell defect in patients with ADA deficiency $(3,4)$.

Our results do not rule out the possbility that local concentrations of extracellular adenosine may be transiently elevated in $l c k^{\mathrm{NT}}$ transgenic mice compared to control littermates, even to the point where $A_{2 a}$ or $A_{2 b}$ receptors might be engaged. However, if this happened, it did not result in a phenotype that we were able to detect.

The enormous capacity of thymocytes to produce adenosine and the role of ADA in maintaining low thymic adenosine levels are also shown by the concentration of adenosine which accumulates when mice are treated with the ADA inhibitor 2'-deoxycoformycin (dCF) (see below). Adenosine can be metabolized by two major routes: either by phosphorylation to AMP by adenosine kinase followed by deamination to inosine 5'-monophosphate (IMP) by AMP deaminase and dephosphorylation by cytoplasmic $5^{\prime}-\mathrm{NT}$, or by direct deamination to inosine by ADA (Fig. 4). At this point, the two pathways merge and inosine undergoes phosphorolysis to hypoxanthine, followed by either salvage to IMP or degradation to uric acid depending on the metabolic needs of the cell. Adenosine kinase has a lower $K_{M}$ for adenosine than ADA, but in the thymus ADA has a much higher overall activity. Thus, Snyder and Lukey (34) assert that deamination will be favored over phosphorylation in the murine thymus even at adenosine concentrations as low as $100 \mathrm{nM}$. Our measurements of thymic adenosine levels in normal mice predict that adenosine concentrations will be in the $1.4-\mu \mathrm{M}$ range. In normal (i.e., nontransgenic) mice treated with dCF $3 \mathrm{~h}$ before death, adenosine concentrations were elevated over 30 -fold to an average concentration of $54 \mu \mathrm{M}$. Similarly, adenosine levels in the thymuses of neonatal ADA knockout mice were elevated 100fold (6). Even in ADA knockout mice rescued with an ADA minigene which directs ADA expression to the placenta and gastrointestinal tract, thymic adenosine levels were still 7.3fold elevated compared to mice with systemic ADA expres- 
sion, and were seven- to eightfold higher than those of deoxyadenosine (7). This indicates that adenosine is produced in the thymus at a greater rate than can be accomodated by the activity of adenosine kinase alone, and confirms Snyder's and Lukey's prediction that deamination is the major route of adenosine metabolism in the thymus.

Adenosine has lost favor as the toxic metabolite in ADA deficiency for a number of reasons. First, systemic adenosine levels are not elevated nearly as much as those of deoxyadenosine in ADA deficient patients $(3,4)$. Second, deoxyadenosine can mediate toxicity to lymphocytes via multiple mechanisms including induction of DNA strand breaks (35), suicide inhibition of SAH hydrolase (36), and inhibition of ribonucleotide reductase after its conversion to dATP $(37,38)$. Third, systemic adenosine levels remain elevated in ADA-deficient patients whose immune systems have been reconstituted by bone marrow transplanation (39). However, to our knowledge, adenosine measurements have not been made in thymuses of ADA-deficient children and systemic adenosine levels may not reflect thymic adenosine concentrations after bone marrow reconstitution. Based on our measurements of thymic adenosine concentrations in dCF-treated mice (which are as elevated as deoxyadenosine levels), and our observation that the $\mathrm{A}_{2 \mathrm{a}}$ receptor agonist CGS21680 causes apoptosis of thymocytes in vitro, we predict that the concentration of adenosine that accumulates upon loss of ADA would be sufficient to engage $A_{2 \mathrm{a}}$ receptors and cause apoptosis of thymocytes in vivo. Although the murine thymocyte $A_{2 a}$ receptor has not been extensively characterized, in other species its affinity for adenosine has been estimated at $100 \mathrm{nM}-1.0 \mu \mathrm{M}$ (40). Our results suggest that adenosine receptor-mediated apoptosis of thymocytes could be one factor in the pathogenesis of ADA deficient SCID.

In summary, high levels of $5^{\prime}$-NT expression early in T cell differentiation, when the proximal lck promoter is active, have no apparent deleterious consequences. Although it is still possible that $5^{\prime}$-NT expression could be harmful at even earlier stages in maturation, it would appear that $5^{\prime}$-NT expression is upregulated in medullary thymocytes because of some specific, but presently unidentified, function of the enzyme at that stage of development. The creation of $5^{\prime}$-NT knockout mice may be needed to address this issue. The study of $l c k^{\mathrm{NT}}$ transgenic mice has revealed insights into purine metabolism in the thymus relevant for both normal T lymphopoiesis and the pathophysiology of T cell disease states such as ADA deficiency.

\section{Acknowledgments}

The authors wish to thank Dr. Roger Perlmutter for the generous gift of the p1017 vector, Dr. Yukio Ikehara for the human 5'-NT cDNA, Dr. Janko Nikolic-Zugic for the H-Y TCR transgenic mice, Dr. Martin Low for phosphatidylinositol-specific phospholipase C, ParkeDavis for 2-deoxycoformycin, and Dr. Max Cooper and Dr. Jeffrey Bluestone for monoclonal antibodies. We also thank Dr. Paul Kincade for critical comments regarding the manuscript, Viji Dandapani for excellent technical assistance with the flow cytometric analyses, and the OASIS Word Processing Center at OMRF for production of the figures.

This work was supported by National Institutes of Health grants CA61802 (R. Resta), AI18220 (L.F. Thompson), GM39699 (L.F. Thompson), and HD30302 (T.B. Knudsen). The Transgenic Mouse Facility at The University of Tulsa was supported by The Oklahoma Center for the Advancement of Science and Technology (OCAST).

\section{References}

1. Ma, D.D.F., T.A. Sylwestrowicz, S. Granger, M. Massaia, R. Franks, G. Janossy, and A.V. Hoffbrand. 1982. Distribution of terminal deoxynucleotidyl transferase and purine degradative and synthetic enzymes in subpopulations of human thymocytes. J. Immunol. 129:1430-1435.

2. Chechik, B.E., W.P. Schrader, and J. Minowada. 1981. An immunomorphologic study of adenosine deaminase distribution in human thymus tissue, normal lymphocytes, and hematopoietic cell lines. J. Immunol. 126:1003-1007.

3. Hershfield, M.S., and B.S. Mitchell. 1995. Immunodeficiency diseases caused by adenosine deaminase deficiency and purine nucleoside phosphorylase deficiency. Hum. Mol. Genet. 4:1725-1768.

4. Hirschhorn, R. 1995. Adenosine deaminase deficiency: molecular basis and recent developments. Clin. Immunol. Immunopathol. 76:S219-S227.

5. Hershfield, M.S., N.M. Kredich, D.R. Ownby, and R. Buckley. 1979. In vivo inactivation of erythrocyte S-adenosylhomocysteine hydrolase by 2 '-deoxyadenosine in adenosine deaminase-deficient patients. J. Clin. Invest. 63:807811.

6. Migchielsen, A.A.J., M.L. Breuer, M.A. van Roon, H. te Riele, C. Zurcher, F. Ossendorp, S. Toutain, M.S. Hershfield, A. Berns, and D. Valerio. 1995. Adenosine-deaminase-deficient mice die perinatally and exhibit liver-cell degeneration, atelectasis and small intestinal cell death. Nat. Genet. 10:279-287.

7. Blackburn, M.R., S.K. Datta, M. Wakamiya, B.S. Vartabedian, and R.E. Kellems. 1996. Metabolic and immunologic consequences of limited adenosine deaminase expression in mice. J. Biol. Chem. 271:15203-15210.

8. Ratter, F., M. Germer, T. Fischbach, K. Schulze-Osthoff, M.E. Peter, W. Dröge, P.H. Krammer, and V. Lehmann. 1996. S-adenosylhomocysteine as a physiological modulator of Apo-1-mediated apoptosis. Int. Immunol. 8:11391147.

9. Kizaki, H., H. Shimada, F. Ohsaka, and T. Sakurada. 1988. Adenosine, deoxyadenosine, and deoxyguanosine induce DNA cleavage in mouse thymocytes. J. Immunol. 141:1652-1657.

10. Kizaki, H., K. Suzuki, T. Tadakuma, and Y. Ishimura. 1990. Adenosine receptor-mediated accumulation of cyclic AMP-induced T lymphocyte death through internucleosomal DNA cleavage. J. Biol. Chem. 265:5280-5284.

11. McConkey, D.J., S. Orrenius, and M. Jondal. 1990. Agents that elevate cAMP stimulate DNA fragmentation in thymocytes. J. Immunol. 145:12271230

12. Lalli, E., P. Sassone-Corsi, and R. Ceredig. 1996. Block of T lymphocyte differentiation by activation of the cAMP-dependent signal transduction pathway. EMBO J. 15:528-537.

13. Widlin, R.S., A.M. Garvin, S. Pawar, D.B. Lewis, K.M. Abraham, K.A. Forbush, S.F. Ziegler, J.M. Allen, and R.M. Perlmutter. 1991. Developmental regulation of lck gene expression in T lymphocytes. J. Exp. Med. 173:383-393.

14. Misumi, Y., S. Ogata, K. Ohkubo, S. Hirose, and Y. Ikehara. 1990. Primary structure of human placental 5 '-nucleotidase and identification of the glycolipid anchor in the mature form. Eur. J. Biochem. 191:563-569.

15. Chaffin, K.E., C.R. Beals, T.M. Wilkie, K.A. Forbush, M.I. Simon, and R.M. Perlmutter. 1990. Dissection of thymocyte signaling pathways by in vivo expression of pertussis toxin ADP-ribosyltransferase. EMBO J. 9:3821-3829.

16. Hogan, B., R. Beddington, F. Costantini, and E. Lacy. 1994. Manipulating the Mouse Embryo: A Laboratory Manual. Cold Spring Harbor Laboratory, Cold Spring Harbor, NY. 497 pp.

17. Fox, R.I., L.F. Thompson, and J.R. Huddlestone. 1981. T cells express T-lymphocyte associated antigens. J. Immunol. 126:2062-2063.

18. Thompson, L.F., J.M. Ruedi, A. Glass, G. Moldenhauer, P. Moller, M.G. Low, M.R. Klemens, M. Massaia, and A.H. Lucas. 1990. Production and characterization of monoclonal antibodies to the glycosyl phosphatidylinositolanchored lymphocyte differentiation antigen ecto-5'-nucleotidase (CD73). Tissue Antigens. 35:9-19.

19. Dorken, B., P. Moller, A. Pezzutto, R. Schwartz-Albiez, and G. Moldenhauer. 1989. B cell antigens: CD73. In Leucocyte Typing IV: white cell differentiation antigens. W. Knapp, et al. editors. Oxford University Press, New York. 102-104.

20. Thompson, L.F., G.R. Boss, H.L. Spiegelberg, I.V. Jansen, R.D. O'Connor, T.A. Waldmann, R.N. Hamburger, and J.E. Seegmiller. 1979. Ecto-5'-nucleotidase activity in $\mathrm{T}$ and $\mathrm{B}$ lymphocytes from normal subjects and patients with congenital X-linked agammaglobulinemia. J. Immunol. 123:2475-2478.

21. Kisielow, P., H. Bluthmann, U.D. Staerz, M. Steinmetz, and H. von Boehmer. 1988. Tolerance in T cell receptor transgenic mice involves deletion of non-mature CD4+8- thymocytes. Nature (Lond.). 333:742-746.

22. Leo, O., M. Foo, D.H. Sachs, L.E. Samelson, and J.A. Bluestone. 1987. Identification of a monoclonal antibody specific for murine T3 polypeptide. Proc. Natl. Acad. Sci. USA. 84:1374-1378.

23. Blackburn, M.R., X. Gao, M.J. Airhart, R.G. Skalko, L.F. Thompson, and T.B. Knudsen. 1992. Adenosine levels in the postimplantation mouse uterus: quantitation by HPLC-fluorometric detection and spatiotemporal regulation by $5^{\prime}$-nucleotidase and adenosine deaminase. Dev. Dyn. 194:155-168.

24. Knudsen, T.B., R.S. Winters, S.K. Otey, M.R. Blackburn, M.J. Airhart, J.K. Church, and R.G. Skalko. 1992. Effects of (R)-Deoxycoformycin (Pentostatin) on intrauterine nucleoside catabolism and embryo viability in the pregnant mouse. Teratology. 45:91-103. 
25. Nicoletti, I., G. Migliorati, M.C. Pagliacci, F. Grignani, and C. Riccardi. 1991. A rapid and simple method for measuring thymocyte apoptosis by propidium iodide staining and flow cytometry. J. Immunol. Methods. 139:271-279.

26. Widnell, C.C., Y. Schneider, B. Pierre, P. Baudhuin, and A. Trouet. 1982. Evidence for a continual exchange of $5^{\prime}$-nucleotidase between the cell surface and cytoplasmic membranes in cultured rat fibroblasts. Cell. 28:61-70.

27. Herman, A., J.W. Kappler, P. Marrack, and A.M. Pullen. 1991. Superantigens: Mechanism of T-cell stimulation and role in immune responses. Аппи. Rev. Immunol. 9:745-772.

28. Stehle, J.H., S.A. Rivkees, J.J. Lee, D.R. Weaver, J.D. Deeds, and S.M. Reppert. 1992. Molecular cloning and expression of the cDNA for a novel A2adenosine receptor subtype. Mol. Endocrinol. 6:384-393.

29. Puffinbarger, N.K., K.R. Hansen, R. Resta, A.B. Laurent, T.B. Knudsen, J.L. Madara, and L.F. Thompson. 1995. Production and characterization of multiple antigenic peptide antibodies to the adenosine $\mathrm{A}_{2 \mathrm{~b}}$ receptor. Mol. Pharmacol. 47:1126-1132.

30. Jiang, H., N.K. Puffinbarger, R. Resta, and L.F. Thompson. 1996. Adenosine receptor expression in developing murine thymus. FASEB J. 10:A1047 (Abstr.)

31. Palmer, T.M., and G.L. Stiles. 1995. Review: Neurotransmitter receptors VII: adenosine receptors. Neuropharmacology. 34:683-694.

32. Bursch, W., S. Paffe, B. Putz, G. Barthel, and R. Schulte-Hermann. 1990. Determination of the length of the histological stages of apoptosis in normal liver and in altered hepatic foci of rats. Carcinogenesis (Lond.). 11:847-853.
33. Thompson, L.F. 1985. Ecto-5'-nucleotidase can provide the total purine requirements of mitogen-stimulated human $\mathrm{T}$ cells and rapidly dividing human B lymphoblastoid cells. J. Immunol. 134:3794-3797.

34. Snyder, F.F., and T. Lukey. 1980. Purine ribonucleoside and deoxyribonucleoside metabolism in thymocytes. Adv. Exp. Med. Biol. 122B:259-264.

35. Seto, S., C.J. Carrera, M. Kubota, D.B. Wasson, and D.A. Carson. 1985 Mechanism of deoxyadenosine and 2-chlorodeoxyadenosine toxicity to nondividing human lymphocytes. J. Clin. Invest. 75:377-383.

36. Hershfield, M.S. 1979. Apparent suicide inactivation of human lymphoblast S-adenosylhomocysteine hydrolase by 2 -deoxyadenosine and adenine arabinoside. J. Biol. Chem. 254:22-25.

37. Mitchell, B.S., E. Mejias, P.E. Daddona, and W.N. Kelley. 1978. Purinogenic immunodeficiency diseases: Selective toxicity of deoxyribonucleosides for T cells. Proc. Natl. Acad. Sci. USA. 75:5011-5014.

38. Ullman, B., L.J. Gudas, A. Cohen, and D.W. Martin, Jr. 1978. Deoxyadenosine metabolism and cytotoxicity in cultured mouse T lymphoma cells: a model for immunodeficiency disease. Cell. 14:365-375.

39. Hirschhorn, R., V. Roegner-Maniscalco, and L. Kuritsky. 1981. Bone marrow transplantation only partially restores purine metabolites to normal in adenosine deaminase-deficient patients. J. Clin. Invest. 68:1387-1393.

40. Bruns, R.F., G.H. Lu, and T.A. Pugsley. 1986. Characterization of the A2 adenosine receptor labeled by $\left[{ }^{3} \mathrm{H}\right] \mathrm{NECA}$ in rat striatal membranes. Mol. Pharmacol. 29:331-346. 